\title{
Umbilical and middle cerebral arteries Doppler velocimetry in early and late onset pre-eclampsia
}

\author{
Bilal Sulaiman $^{1 *}$, Aliyu Y. Isah ${ }^{1}$, Habiba I. Abdullahi ${ }^{1}$, Nathaniel Adewole ${ }^{1}$, \\ Oluwatunmobi R. Opadiran ${ }^{2}$, Usman Suleiman ${ }^{3}$, Rukayya Ibrahim ${ }^{4}$, Bisallah A. Ekele
}

\author{
${ }^{1}$ Department of Obstetrics and Gynaecology, University of Abuja Teaching Hospital, Gwagwalada, FCT, Nigeria \\ ${ }^{2}$ Clinical Department, Bridge Clinic, FCT, Abuja, Nigeria \\ ${ }^{3}$ Department of Obstetrics and Gynaecology, Federal Medical Centre, Gusau, Zamfara, Nigeria \\ ${ }^{4}$ Department of Obstetrics and Gynaecology, Usmanu Danfodiyo University Teaching Hospital, Sokoto, Nigeria
}

Received: 27 November 2021

Accepted: 28 December 2021

\author{
*Correspondence: \\ Dr. Bilal Sulaiman, \\ E-mail: sulaimanbilal2@gmail.com
}

Copyright: (C) the author(s), publisher and licensee Medip Academy. This is an open-access article distributed under the terms of the Creative Commons Attribution Non-Commercial License, which permits unrestricted non-commercial use, distribution, and reproduction in any medium, provided the original work is properly cited.

\section{ABSTRACT}

Background: Pre-eclampsia (PE) is a multisytemic disorder originating from the placenta with a high prevalence in sub-Saharan Africa. Early (<34 weeks) and late ( $\geq 34$ weeks) - onset PE have different maternal and perinatal outcomes with overlapping clinical features. Differences in Doppler velocimetry pattern in these subgroups appears unsettled.

Methods: In a prospective cohort study, 110 pregnant women with singleton pregnancy diagnosed with PE were recruited and had umbilical and middle cerebral arteries (MCA) Doppler velocimetry done. The pregnancies were followed up to delivery and outcome recorded and analysed using Microsoft excel 2013. Student t-test and Chi-squared test were used for continuous and categorical variables respectively. Level of significance was set at less than 0.05 .

Results: There were $53(49.1 \%)$ women with early - onset preeclampsia and $55(50.9 \%)$ with late-onset PE. The mean age of women was $30.30 \pm 5.2$ years. The mean umbilical artery, middle cerebral artery pulsatility indices (PI) and cerebroplacental ratio $(\mathrm{CPR})$ were $1.3 \pm 0.5,1.1 \pm 0.5$ and $1.1 \pm 1.2$ respectively. There was statistical significant difference between the umbilical artery PI $(\mathrm{p}<0.001)$, middle cerebral artery PI $(\mathrm{p}<0.05)$ and CPR $(\mathrm{p}<0.001)$ between early onset and late onset preeclamptic women. The resistance index and systolic diastolic ratio of both the umbilical and middle cerebral arteries were similar between the two groups $(\mathrm{p}>0.05)$.

Conclusions: This study showed that umbilical and middle cerebral artery PI and CPR may be the most important Doppler parameters to watch-out for in monitoring women with PE.

Keywords: Umbilical artery, MCA, Doppler, Early, Late onset preeclampsia

\section{INTRODUCTION}

Preeclampsia (PE), a pregnancy-related disorder is a major cause of maternal and new born morbidity and mortality especially in resource constraint environment. ${ }^{1}$ It occurs in the second half of pregnancy and can affect all maternal systems and the fetus. ${ }^{2}$ Some of the fetal manifestations include intrauterine growth restriction, preterm birth and small for gestation. It has been documented that fetuses with intrauterine growth restriction (IUGR) or preterm birth are at risk of life long sequelae like hypertension and type 2 diabetes mellitus. ${ }^{3}$ Global estimate revealed that PE affects $4.6 \%$ of all pregnancies. ${ }^{4}$ In Nigeria, it contributes $20.5 \%$ and $29 \%$ of maternal death and near miss respectively. ${ }^{5} \mathrm{PE}$ affects $6.4 \%$ of pregnancy in our institution while a prevalence of up to $16 \%$ had been reported in Nigeria. ${ }^{6.7}$

Attention is now growing away from classifying PE as mild and severe PE. ${ }^{8,9}$ The most recent is the classification into early-onset PE, preterm PE, late-onset PE and term PE. ${ }^{9}$ This classification is based on time of delivery. Early 
onset PE is one that develops before 34 weeks while late onset $\mathrm{PE}$ is a one that develops at/after 34 weeks of gestation. ${ }^{9-11}$ In both types of PE delivery is before and after 34 weeks respectively. Both are associated with different maternal and perinatal outcomes and with overlapping clinical features.

The pathophysiology of PE is centred on uteroplacental circulation. While early onset $\mathrm{PE}$ is linked to poor placentation and IUGR, the late onset PE is linked to maternal factors. ${ }^{11}$ In early-onset PE, the placental dysfunction is said to be extrinsic to the placenta, due to incomplete spiral artery remodelling in early pregnancy while in late-onset $\mathrm{PE}$, the cause is said to be intrinsic to the growing and ageing placenta, limiting intervillous perfusion. ${ }^{11,12}$ Both pathologies lead to secondary syncytiotrophoblast stress and release of pro-inflammatory factors into the maternal circulation. ${ }^{11,12}$

It has been established that, the blood flow velocity of the uterine, umbilical and middle cerebral arteries and ductus venoses can be assessed using Doppler ultrasonography including the blood floor volume, direction and impedance. ${ }^{13}$ Doppler tool can be applied to identify fetuses at risk of PE complication like IUGR or monitor those already affected. The features of the blood flow of the arteries can be assessed using various parameters like peak systolic velocity (PSV), end diastolic velocity (EDV), and various mathematical combinations of PSV and EDV like pulsatility index (PI), resistance index (RI) and systolic diastolic (S/D) ratio. ${ }^{14}$ These are the most commonly used parameter in obstetrics and are highly correlated. ${ }^{14,15}$ Pulsatility (Goslin) index is derived from maximum, minimum and mean Doppler frequency shift during a cardiac cycle. ${ }^{16}$ Mathematically, it is represented as given below. ${ }^{13}$

\section{$P I=$ Peak systolic velocity-end diastolic velocity /mean velocity}

It shows a linear correlation with vascular resistance and does not approach infinity when there are absent or reversed diastolic values. ${ }^{14} \mathrm{PI}$ is the most commonly used index in obstetrics. ${ }^{14}$ Resistance (Pourcelot) index is derived from maximum and minimum velocity is given below.

\section{$R I=$ Peak systolic velocity - end diastolic velocity /peak systolic velocity}

While SD ratio is peak systolic velocity by end diastolic velocity. ${ }^{13}$ Both RI and SD ratio show a parabolic relationship with increasing vascular resistance. ${ }^{14}$ Cerebroplacental ratio (CPR) has recently emerged as an important predictor of adverse pregnancy outcome and has been recommended to be considered in the assessment of fetuses in $3^{\text {rd }}$ trimester irrespective of the values of the umbilical and middle cerebral arteries.$^{16}$ It is the ratio between the middle cerebral artery (MCA) PI to the uterine artery (UA) PI (MCA PI/UA PI). CPR represents the interaction of alteration in blood flow to the brain as manifest by increased diastolic flow as the result from hypoxia and increased placental resistance, resulting in a decreased diastolic flow of the umbilical artery. ${ }^{17}$ A low CPR indicates redistribution of blood floor to the cerebral circulation and is associated with adverse outcome than Doppler indices of UA and MCA alone. ${ }^{17}$ Various studies were conducted on preeclampsia/eclampsia in our subregion with very few paying attention to early onset PE. Despite this, no available literature on Doppler velocimetry comparing early and late onset PE in the sub region could be found. This study was set out to compare the pattern of Doppler velocimetry indices as monitoring tools in the settings of early and late onset preeclampsia. Critical values of the indices beyond which a likely adverse fetal outcome may ensue are also documented for clinical use.

\section{METHODS}

This was a prospective comparative study involving 110 women. One hundred and eight women (108) eventually completed the study comprising 53 early-onset and 55 late-onset PE that was conducted at a Teaching Hospital in a suburb of Abuja, Nigeria over a two-year period (November 2018-October 2020). All women at the antenatal clinic or ward with a singleton pregnancy, blood pressure $\geq 140 / 90 \mathrm{mmHg}$ with proteinuria or any feature of PE using ISSHP criteria at or greater than 20 weeks gestational age were included in the study. ${ }^{18}$ Women with chronic hypertension, renal disease in pregnancy, congenital anomalies, multiple pregnancies, antepartum haemorrhage and anaemia in pregnancy were excluded from the study. The sample population was obtained using GPower software and a total of 98 at a ratio of 1:1 was obtained. With a $10 \%$ attrition rate, 110 women were recruited. Women were recruited using a random sampling method. The women were grouped into early-onset and late-onset PE based on the gestation age at diagnosis of PE. Basic scan was conducted to confirm the location and viability of the singleton pregnancy. An umbilical and middle cerebral arteries Doppler velocimetry were conducted using GE voluson P8 with a curvilinear transabdominal transducer (3.5 MHZ). A free loop of the umbilical cord was identified and the angle of insonation was set at $<20^{\circ}$ with a gate size $<2 \mathrm{~mm}$ during the Doppler interrogation. An axial section of the brain, including the thalami and the sphenoid bone wings was obtained and magnified. Colour flow mapping was used to identify the circle of Willis and the proximal MCA. The pulsed-wave Doppler gate was then placed at the proximal third of the MCA, close to its origin in the internal carotid. The angle between the ultrasound beam and the direction of blood flow was kept as close as possible to $0^{0}$. Doppler values were obtained three times using auto trace and the mean value was recorded. Parameters recorded were PI, RI, and SD ratio which were obtained automatically without fetal breath and/or movement. Then cerebrospinal ratio $(\mathrm{CPR}=\mathrm{MCAPI} / \mathrm{UAPI})$ was calculated. The 
ultrasonography was conducted by an obstetrician with specialisation in maternal-fetal medicine. The pregnancies were followed up to delivery and fetal outcomes were recorded. Data was recorded and analysed using Microsoft excel 2013.

Chi squared test and Student's t-test were used for categorical and continuous variables respectively. The level of significance was set at $p$ value $<0.05$.

\section{RESULTS}

Only one hundred and eight (108) women completed the study. The women were grouped into early onset [53 $(49.1 \%)$ ] and late-onset [55 (50.9\%)] PE. The mean age of all the participants was $30.30 \pm 5.2$ years with no significant difference between the 2 groups $(\mathrm{p}=0.817)$. There were significant differences in booking status $(p=0.000)$, gestational age at diagnosis $(\mathrm{p}=0.000)$, and gestational age at delivery $(\mathrm{p}=0.000)$ between the 2 groups (Table 1$)$.

The mean uterine artery PI in the early-onset PE $(1.67 \pm 0.35)$ was significantly higher than that of late-onset PE $(0.94 \pm 0.34),(p=0.000)$. MCA PI in early onset PE group $(1.04 \pm 0.49)$ was statistically lower $(\mathrm{p}=0.049)$ than the MCA PI in the late onset group $(1.21 \pm 0.45)$. The overall mean CPR was $1.1 \pm 1.2$. The CPR in early onset PE $(0.63 \pm 0.36)$ was lower than $\mathrm{CPR}$ in late onset $\mathrm{PE}$ $(1.56 \pm 1.54)$. This was demonstrated to be statistically significant $(\mathrm{p}=0.000)$. Other Doppler parameters were similar between the 2 groups (Table 2 ).

Only $4(3.7 \%)$ fetuses had IUGR in which $1(0.9 \%)$ occurred in the late onset PE group. However, there was no statistical difference in the IUGR between the two groups. Mode of delivery $(\mathrm{p}=0.00)$ and live birth $(\mathrm{p}=0.018)$ were shown to be statistically significant (Table 3 ).

Table 1: Baseline characteristics.

\begin{tabular}{|c|c|c|c|}
\hline Characteristics & $\begin{array}{l}\text { Early onset Preeclampsia } \\
\text { (mean, mode or frequency) }\end{array}$ & $\begin{array}{l}\text { Late onset preeclampsia } \\
\text { (mean, mode or frequency) }\end{array}$ & P value \\
\hline Age & $30.42 \pm 4.5$ & $30.18 \pm 5.82$ & 0.817 \\
\hline Parity & 0 & 1 & \multirow{4}{*}{0.000} \\
\hline \multicolumn{3}{|l|}{ Booking status } & \\
\hline Booked & 27 & 47 & \\
\hline Not booked & 26 & 8 & \\
\hline Gestational age at diagnosis & $29.42 \pm 2.4$ & $36.20 \pm 2.3$ & 0.000 \\
\hline Gestational age at delivery & $31.58 \pm 2.9$ & $36.20 \pm 2.3$ & 0.000 \\
\hline Weight & $74.31 \pm 16.9$ & $75.07 \pm 14.706$ & 0.804 \\
\hline Systolic BP & $163.11 \pm 18.4$ & $162.31 \pm 17.229$ & 0.815 \\
\hline Diastolic BP & $95.96 \pm 7.9$ & $96.9 \pm 9.7$ & 0.591 \\
\hline
\end{tabular}

Table 2: Relationship between umbilical and middle cerebral artery velocimetry and the onset of preeclampsia.

\begin{tabular}{|lllllc|}
\hline Parameter & $\begin{array}{l}\text { Early onset } \\
\text { preeclampsia }\end{array}$ & $\begin{array}{l}\text { Late onset } \\
\text { preeclampsia }\end{array}$ & t-test & P value & 95\% CI \\
\hline UA PI & $1.67 \pm 0.35$ & $0.94 \pm 0.34$ & 10.519 & 0.000 & $0.608-0.890$ \\
\hline UA RI & $0.60 \pm 0.05$ & $0.59 \pm 0.045$ & 0.950 & 0.344 & $0.009-0.027$ \\
\hline SD & $2.58 \pm 0.312$ & $2.56 \pm 0.28$ & 0.307 & 0.760 & $0.095-0.130$ \\
\hline MCA PI & $1.04 \pm 0.49$ & $1.21 \pm 0.45$ & -1.979 & 0.049 & $-0.363-0.000$ \\
\hline MCA RI & $0.62 \pm 0.15$ & $0.59 \pm 0.049$ & 1.273 & 0.206 & $-0.015-0.071$ \\
\hline MCA SD & $2.58 \pm 0.31$ & $2.56 \pm 0.28$ & 0.307 & 0.760 & $-0.095-0.130$ \\
\hline CPR & $0.63 \pm 0.36$ & $1.56 \pm 1.54$ & -4.257 & 0.000 & $-1.355-0.495$ \\
\hline
\end{tabular}

Table 3: Relationship between the onset of PE and fetal outcome.

\begin{tabular}{|c|c|c|c|}
\hline Outcome & Early onset PE & Late onset PE & P-value \\
\hline IUGR & & & \multirow{3}{*}{0.291} \\
\hline Present & 3 & 1 & \\
\hline Absent & 50 & 54 & \\
\hline \multicolumn{3}{|l|}{ Mode of delivery } & \multirow{4}{*}{0.000} \\
\hline Vaginal delivery & 37 & 29 & \\
\hline Caesarean section & 6 & 26 & \\
\hline Abortion & 8 & 0 & \\
\hline Live birth & & & 0.018 \\
\hline
\end{tabular}




\begin{tabular}{|c|c|c|c|}
\hline Outcome & Early onset PE & Late onset PE & P-value \\
\hline Alive & 39 & 50 & \\
\hline Still birth & 14 & 5 & \\
\hline \multicolumn{3}{|c|}{ NICU admission } & \multirow{3}{*}{0.17} \\
\hline Yes & 23 & 12 & \\
\hline No & 30 & 43 & \\
\hline
\end{tabular}

\section{DISCUSSION}

In this study there were $53(49.1 \%)$ and $55(50.9 \%)$ cases of early and late onset PE respectively. The mean age of the women was $30.3 \pm 5.2$ years and there was no statistical significant difference between the two groups. This is consistent with the observation in the Polish population. ${ }^{8,19}$ There were more women that booked the pregnancy in the late-onset group compared to the early onset group. This was shown to be statistically significant. The booking and subsequent antenatal care especially in early pregnancy can influence the development and progression of PE disease. Regular monitoring and interventions like use of low dose aspirin had been proven to reduce the occurrence of preeclampsia. ${ }^{9}$ The mean gestational age at diagnosis in the early and late onset PE group were 29.4 and 36.2 weeks respectively. The age of diagnosis in early onset group from our study is lower compared to the findings by Wojtowicz et al. ${ }^{8} \mathrm{PE}$ is found to be higher in our sub region when compared to Europe where there is improved socioeconomic status and mostly an insurance coverage as early as 10 weeks for all pregnant women. ${ }^{1,8}$ Therefore the low socio-economic status in this region may have posed a challenge of poor antenatal care in early pregnancy where women at risk of (early onset) PE can be identified and appropriate intervention instituted.

Our observation of UA PI, RI and SD ratio in this study were similar to finding by Adekanmi et al. ${ }^{20}$ These may be explained by similarities in bio-demographic characteristics of the participants in both studies. It was however observed in our study that the UA PI is lower in the early onset group compared to the late onset group $(p<0.001)$. This is in agreement with the observation by Kornacki and Skrzpczak in Europe. ${ }^{19}$ The MCA PI in the early onset group was significantly lower than the late onset group $(\mathrm{p}<0.05)$. This observation was in contrast to findings from Poland. ${ }^{19}$ The CPR in the late onset group was higher than the early onset group $(p<0.001)$. The CPR in late onset group from our study was similar to that of Polish study while that of early onset group was in contrast. It is opined that from our study, the umbilical and middle cerebral artery PI and CPR may be the most important Doppler parameters to look for in monitoring fetuses in PE disease.

There were $4(3.7 \%)$ cases of IUGR in this study of which 3 (2.8) of the fetuses were from the early onset group. This was found to be likely a chance occurrence and comparable to the observation by Kornacki and Skrzpczak where they found no statistical significant difference in IUGR between the two groups. ${ }^{19}$
The difference in mode of delivery between the two groups is statistically significant. More women had caesarean section in the late onset PE group when compared to the early onset group while abortion is only found in the early onset group. The latter may be because of the gestational age at diagnosis in the early onset group since termination of pregnancy before the age of viability is admissibly, an abortion. Only $5(4.6 \%)$ perinatal mortalities were recorded in the late onset group. There was statistical significant difference in perinatal mortality between the two groups. Similar findings were earlier reported in the retrospective studies by Wojtowicz et al, in Poland and Ebeigbe and Aziken in Nigeria. ${ }^{8,21}$

It is however noted that there was no perinatal death in the late-onset group from the polish study while the Nigerian study used the older classification of the hypertension in pregnancy which makes it difficult to compare results.

\section{CONCLUSION}

Our study showed that the umbilical and middle cerebral artery PI and CPR may be the most important Doppler parameters to look for in monitoring fetuses in women with preeclampsia. Furthermore, women with late-onset PE had as expected, better perinatal outcome as compared with early-onset preeclampsia. It is clear that women who booked their pregnancy as noticed in the late-onset PE group had the chance for intake of low dose aspirin which has remained a valuable intervention in the prevention of $\mathrm{PE}$ and its overall outcome. There is need to carry out further studies with a larger sample size in our environment for evidence to be conclusive.

\section{ACKNOWLEDGMENTS}

Authors would like to acknowledge the wonderful technical supports of the head of obstetrics and gynaecology department, Professor T. E. Agida and Mrs. J. T. Ajayi during the study period.

Funding: No funding sources Conflict of interest: None declared

Ethical approval: The study was approved by the Institutional Ethics Committee

\section{REFERENCES}

1. Steegers EA, von Dadelszen P, Duvekot JJ, Pijnenborg R. Pre-eclampsia. Lancet. 2010;376(9741):631-44. 
2. Mayrink J, Costa ML, Cecatti JG. Preeclampsia in 2018: Revisiting Concepts, Physiopathology, and Prediction. Scientif World J. 2018;6268276.

3. Longo S, Bollani L, Decembrino L, Di Comite A, Angelini M, Stronati M. Short-term and long-term sequelae in intrauterine growth retardation (IUGR). J Matern Fetal Neonatal Med. 2013;26(3):222-5.

4. Abalos E, Cuesta C, Grosso AL, Chou D, Say L. Global and regional estimates of preeclampsia and eclampsia: a systematic review. Eur J Obstet Gynecol Reprod Biol. 2013;170(1):1-7.

5. Oladapo OT, Adetoro OO, Ekele BA, Chama C, Etuk $\mathrm{SJ}$, Aboyeji AP, et al. When getting there is not enough: a nationwide cross-sectional study of 998 maternal deaths and 1451 near-misses in public tertiary hospitals in a low-income country. BJOG. 2016;123:928-38.

6. Ayogu ME, Akaba GO, Offiong RA, Adewole ND, Ekele BA. Risk factors for hypertensive disorders of pregnancy in Abuja, Nigeria: A prospective casecontrol study. Trop J Obstet Gynaecol. 2020;37:4652 .

7. Onoh RC, Mamah JE, Umeokonkwo CD, Onwe EO, Ezeonu PO, Okafor L. Severe preeclampsia and eclampsia: A 6-year review at the Federal Teaching Hospital, Abakaliki, Southeast Nigeria. Trop J Obstet Gynaecol. 2019;36:418-23.

8. Wojtowicz A, Zembala-Szczerba A, Babczyk A, Kołodziejczyk-Pietruszka M, Lewaczynska O, Huras H. Early- and Late-Onset Preeclampsia: A Comprehensive Cohort Study of Laboratory and Clinical Findings according to the New ISHHP Criteria. Int J Hypertens. 2019;4108271.

9. Poon LC, Shennan A, Hyet JA, Kapur A, Hadar E, Divakar $\mathrm{H}$, et al. The International Federation of Gynaecology and Obstetrics (FIGO) initiative on preeclampsia: A pragmatic guide for first -trimester screening and prevention. Int $\mathbf{J}$ Gynecol Obstet. 2019;145:1-33.

10. Raymond D, Paterson E. A Critical Review of EarlyOnset and Late-Onset Preeclampsia. Obstet Gynecol Surv. 2011;66(8):497-506.

11. Redman CW. Early and late onset preeclampsia: Two sides of the same coin. Pregnancy Hypertension. 2017;7:58.

12. Staff AC, Redman CWG. The Differences between early- and late-onset pre-eclampsia. In: Saito S, editor. Preeclampsia. Comprehensive Gynecology and Obstetrics. Springer, Singapore. 2018;155-72.
13. Srikumar S, Debnath J, Ravikumar R, Bandhu HC, Maurya VK. Doppler indices of the umbilical and fetal middle cerebral artery at 18-40 weeks of normal gestation: A pilot study. Med J Armed Forces India. 2017;73:232-41.

14. Sotiriadis A, Hernandez-Andrade E, da Silva Costa F, Ghi T, Glanc P, Khalil A, et al. ISUOG Practice Guidelines: role of ultrasound in screening for and follow-up of pre-eclampsia. Ultrasound Obstet Gynecol. 2018;53:7-22.

15. Bhide A, Acharya G, Bilardo CM, Brezinka C, Cafici D, Hernandez-Andrade E, et al. ISUOG Practice Guidelines: use of Doppler ultrasonography in obstetrics. Ultrasound Obstet Gynecol. 2013;41:2339.

16. Ebbing C, Rasmussen S, Kiserud T. Middle cerebral artery blood flow velocities and pulsatility index and the cerebroplacental pulsatility ratio: longitudinal reference ranges and terms for serial measurements. Ultrasound Obstet Gynecol. 2007;30:287-96.

17. DeVore GR. The importance of the cerebroplacental ratio in the evaluation of fetal well-being in SGA and AGA fetuses. Am J Obstet Gynecol. 2015;1-14.

18. Brown MA, Lindheimer M, de Swiet M, Van Assche A, Moutquin JM. The classification and diagnosis of the hypertensive disorders of pregnancy: statement from the International Society for the Study of Hypertension in Pregnancy (ISSHP). Hypertens Pregnancy. 2001;20(1):9-14.

19. Kornacki J, Skrzpczak J. Results of Doppler examination in fetuses of mothers with early and lateonset preeclampsia. Ginekol Pol. 2014;85:504-8.

20. Adekanmi AJ, Roberts A, Akinmoladun JA, Adeyinka AO. Uterine and umbilical artery Doppler in women with pre-eclampsia and their pregnancy outcomes. Niger Postgrad Med J. 2019;26:106-12.

21. Ebeigbe PN, Aziken ME. Early onset pregnancy induced hypertension/eclampsia in Benin City, Nigeria. Niger J Clin Pract. 2010;13(4):388-93.

Cite this article as: Sulaiman B, Isah AY, Abdullahi HI, Adewole N, Opadiran OR, Suleiman U, et al. Umbilical and middle cerebral arteries Doppler velocimetry in early and late onset pre-eclampsia. Int J Reprod Contracept Obstet Gynecol 2022;11:33842. 